\title{
Resource Allocation and Leveling in Construction Management Projects with Resource Histogram
}

\author{
Mohammad Azim Eirgash \\ Department of Civil Engineering, Karadeniz Technical University, Trabzon, Turkey \\ Email address: \\ azim.eirgash@ktu.edu.tr

\section{To cite this article:} \\ Mohammad Azim Eirgash. Resource Allocation and Leveling in Construction Management Projects with Resource Histogram. American \\ Journal of Engineering and Technology Management. Vol. 5, No. 6, 2020, pp. 91-95. doi: 10.11648/j.ajetm.20200506.11
}

Received: December 10, 2020; Accepted: December 17, 2020; Published: December 31, 2020

\begin{abstract}
Resource allocation and leveling in construction management projects have been an enthusiastic subject to plenty of researchers since the advancement of the scheduling techniques. Many researchers have studied various versions of the benchmark resource leveling and allocation optimization problems using various scheduling techniques. However, in this study, a straightforward scheduling technique called resource histogram is utilized to allocate and level the available resources. Moreover, the maximum number of resources at peak time is considered as a significant aspect of the case study. Since peak demand isn't a preferred by the contractor. The effects of resources are also examined in order to demonstrate the variation of the total duration of the project which provides flexibility to decision-makers in making intelligent decisions regarding the use of the resources. Thereby, a construction project with seven activities taken from the technical literature is examined with constrained as well as unconstrained conditions using Microsoft Excel. However, task scheduling is performed using critical path method (CPM). The results indicate that limitation on resources significantly affect the performance and cause the project to be extended beyond the scheduled duration. Moreover, besides renewable, non-renewable resources (e.g., cost demand) may also be significant parameters and this extension can be considered in future research.
\end{abstract}

Keywords: Resource Leveling, Optimization, Resource Histogram, Peak Time, Resource Allocation

\section{Introduction}

Resource allocation or loading is nothing but the assigning required resource to each activity in amount and timing. On another word, resources in construction express 4 main categories contracted as 4Ms (Manpower, money, material and machinery). Assigning the required resources to each activity in amount and timing is known as resource allocation or loading. Resource leveling is the process of allocating resources among various activities such that peak requirement of resource is reduced with a constraint on time. To put it simply, resource leveling is basically minimalizing the variations resource use during the project execution. That means, if the resources are unlimited or infinite, then smoothing or leveling is performed to see the fluctuation. If the resources are restricted or scarce resource is predicted, then allocate it. Resource leveling is required in the project to avoid difficulties with major differences in resource use in the construction works. The resource allocation and leveling have attracted many researcher's attraction in the last decades.
However, reviewing the literature it has been revealed that from the beginning of the 1960s until recently, researchers usually assumed trade-off functions between both the time and the cost $[1,2]$. In recent years, some researchers tried to investigate multi-mode discrete time-cost tradeoff using GAs [3-6]. Later on, many researchers have attempted to find an optimum solution for resource leveling in repetitive project scheduling.

Georgy presented a genetic algorithm for resource leveling using a linear scheduling method (LSM). The author's algorithm adopted function optimizers to overcome the primary shortcoming of mathematical solutions for the resource leveling problem, however it required more resource usage and added variables [7].

Elwany et al. demonstrated a linear programming model for single resource allocation and smoothening in repetitive construction projects. Line of balance (LOB) is widely applied in repetitive projects. LOB performs resource allocation but ignores resource leveling [8].

Rao et al. studied numerous analytical methods for resource 
balancing almost all of them in nature and is intuitive. This is the basic idea of the methods, their non-critical effectiveness, in a systematic order according to some rules. Heuristic methods are huge can handle projects, but the solution they provide is not essentially optimum [9].

Hegazy and Tarek have worked on project scheduling problems in the scheduling process of practitioners. They deal with, especially the projected production of the project the most efficient resource consumption without increasing the time [10]. Sonmez et al. has used genetic algorithm (GA) for the resource levelling problem. Many sample projects are considered to be solved by Microsoft Project 2010 and the performance of these projects are compared with GA. The comparisons reveal that the GA outperforms resource levelling heuristic of Microsoft Project 2010 significantly [11]. Moreover, using non-linear programming exact solutions were obtained for the sample problems. Exact solutions indicate that the algorithm is capable of achieving sufficient solutions. Thereby, for the resource levelling problem GA is a good alternative choice. Lucko in his papar tried to analyze criticality of linear schedules with the unique singularity functions. The new approach which is used to keep resources intact and derives one flexible equation for the complete resource profile of a schedule, including any timing or resource rate changes [12]. Garmsiri and Abassi applied an ant algorithm which determines the execution mode of each activity such that resource leveling index and project time become optimum. In the model, some visibility functions are used, and the best, which return the best result, is selected for the model [13]. In another study Khanzadi et al. have tried to unravel some resource allocation problems. For this purpose, two new metaheuristic algorithms so-called colliding body optimization and charged system search have been applied. Two case examples have been solved to exhibit the applicability and performance of the utilized algorithms [14]. In a similar study Cheng and Tran developed a modern optimization algorithm, the Opposition-based Multiple Objective Differential Evolution (OMODE), to solve the time-cost-utilization work shift tradeoff (TCUT) problem. In this novel algorithm an opposition-based learning technique for population initialization and for generation jumping has been employed. Two sample problems of construction projects indicate the ability of OMODE generated non-dominated solutions to assist project managers to select an appropriate plan to optimize TCUT [15]. Therefore, this paper uses a case study in order to portray how resource leveling could be done using Microsoft Excel and what its effects are on the completion of the project.

In this study, straightaway the methodology is explained. Then, resource allocation and leveling is applied on a small sample project, and the scenarios have been evaluated, and at the end conclusion is given, respectively.

\section{Methodology}

In early years CPM/PERT methods were used for project management. However now a day's project management software have been adopted. It was derived that Primavera Project Planner and MS Project are the most popular software packages used for construction projects. However, in this paper, a simple scheduling engine Microsoft Excel is exerted for both resource constrained as well as unconstrained scenarios. To perform resource levelling following steps are tracked.

1. Identification of critical activities

2. Arrange the activities on time axis based on their early start dates.

3. The total number of resources required on each day are obtained by adding the resource requirements of individual activities on that particular activity, and resource profile determined as chart called resource aggregation (histogram) chart.

4. Repeat steps 2 and 3, with activities plotted using their latest start dates.

5. Compare the two resource charts in steps 3 and 4.

6. An acceptable resource profile between two extremes is found by eliminating the peak and valleys of the resource distribution.

And also resource allocation can be carried out through the following steps.

1. Identify the critical activities in the network.

2. Allocate the resources day-wise.

3. If at any time, the resource requirement exceeds availability, then allocation of resources to activities should follow the rules below.

a) Critical activities get the first preference.

b) On-going activities should not be stopped in the middle.

c) Allocate the resources to activity that has the least EST.

d) If two activities have the same EST, then allocate resources to the activity that has lesser float.

\section{Application}

A project summary of the case study data is given in Table 1. CPM and bar chart representation of present project is demonstrated in Figures 1 and 2. For the following two scenarios, allocating and leveling the resources are performed as per the following scenarios.

1) Assuming the cement bags are available as per requirement i.e. starting all activity at EST (Earliest start time), Find the duration of the project and demonstrate the cement bag histogram.

2) If number of cement bags are restricted to 12 / day. The total duration of the project has to be determined.

Table 1. Case study date of 7 activity.

\begin{tabular}{llllllllll}
\hline Activities & A & B & C & D & E & F & G & H & I \\
\hline Pre. & - & - & B,D & A & A & C & F & C & E,G \\
Dur. (day) & 4 & 3 & 4 & 5 & 6 & 3 & 2 & 7 & 5 \\
Cem. bags & 0 & 5 & 7 & 10 & 6 & 12 & 8 & 6 & 0 \\
Total days & 0 & 15 & 28 & 50 & 36 & 36 & 16 & 42 & 0 \\
\hline
\end{tabular}

$\mathrm{SSB}=223$ bags required for this project work. 


\subsection{First Scenario}

If the quantity of cement bags is unlimited, then the total duration of the project is found to be 23 days. Hence, resource leveling is carried-out on the project since availability of the resource isn't limited.

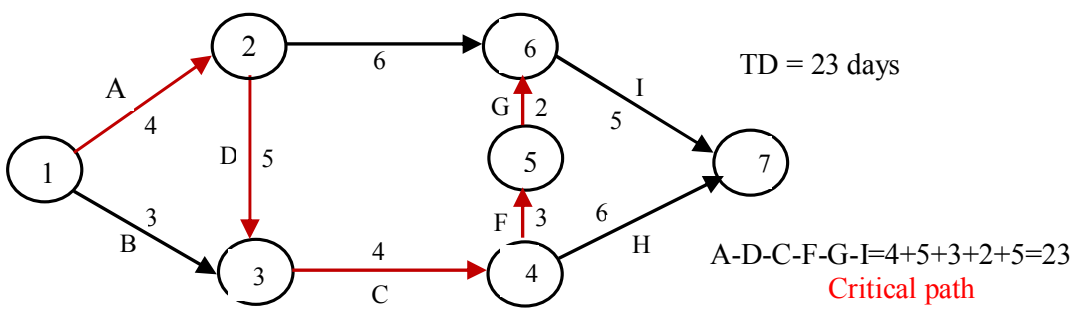

Figure 1. Project Network of 7 activity.

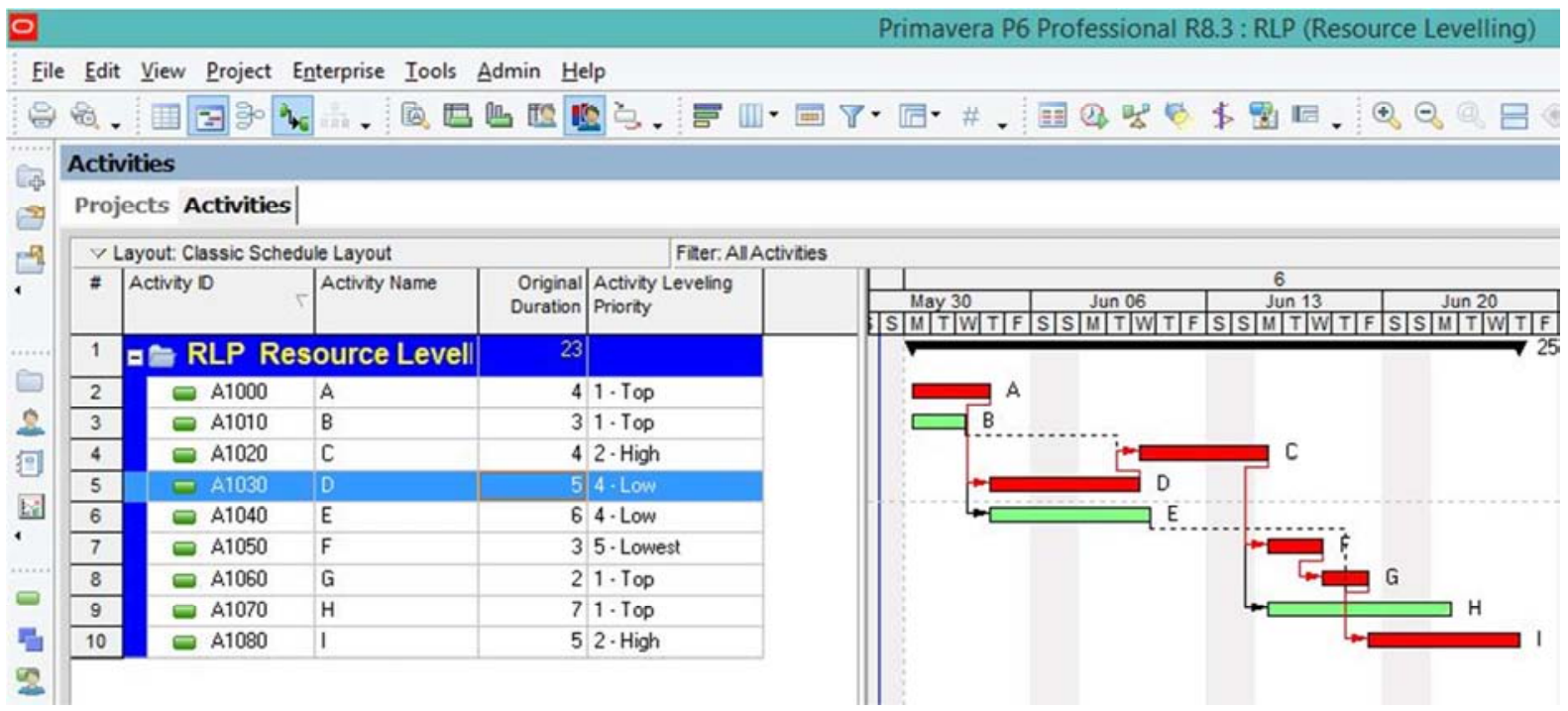

Figure 2. Bar chart of 7 activity project in Oracle Primavera R8.3.

It is observed that the bars with red colors are critical activities i.e. A-C-D-F-G-I which require maximum amount of resources e.g. time duration, cement bag...etc and the bars with green colors are remaining works which are not critical. Figure 3 illustrates the bar chart with the material assignment histogram and a maximum of 18 cement bags per day.

\begin{tabular}{|c|c|c|c|c|c|c|c|c|c|c|c|c|c|c|c|c|c|c|c|c|c|c|c|c|c|c|}
\hline Act. & $\begin{array}{l}\text { Cem. } \\
\text { Bags }\end{array}$ & & & & & & & & & & & & & & & & & & & & & & & & TF & $\begin{array}{l}\text { Tot } \\
\text { Res }\end{array}$ \\
\hline $\mathrm{A}$ & 0 & 0 & 0 & 0 & 0 & & & & & & & & & & & & & & & & & & & & 0 & 0 \\
\hline B & 5 & 5 & 5 & 5 & $x$ & $\mathrm{x}$ & $\mathrm{x}$ & $\mathrm{X}$ & $\mathrm{x}$ & $\mathrm{x}$ & & & & & & & & & & & & & & & 6 & 15 \\
\hline $\mathrm{C}$ & 7 & & & & & & & & & & 7 & 7 & 7 & 7 & & & & & & & & & & & 0 & 28 \\
\hline D & 10 & & & & & 10 & 10 & 10 & 10 & 10 & & & & & & & & & & & & & & & 0 & 50 \\
\hline $\mathrm{E}$ & 6 & & & & & 6 & 6 & 6 & 6 & 6 & 6 & $\mathrm{x}$ & $\mathrm{x}$ & $\mathrm{X}$ & $x$ & $\mathrm{x}$ & $\mathrm{x}$ & $\mathrm{x}$ & $\mathrm{x}$ & & & & & & 8 & 36 \\
\hline $\mathrm{F}$ & 12 & & & & & & & & & & & & & & 12 & 12 & 12 & & & & & & & & 0 & 36 \\
\hline G & 8 & & & & & & & & & & & & & & & & & 8 & 8 & & & & & & 0 & 16 \\
\hline $\mathrm{H}$ & 6 & & & & & & & & & & & & & & 6 & 6 & 6 & 6 & 6 & 6 & 6 & $\mathrm{x}$ & $x$ & $\mathrm{x}$ & 3 & 42 \\
\hline I & 0 & & & & & & & & & & & & & & & & & & 0 & 0 & 0 & 0 & 0 & 0 & 0 & 0 \\
\hline \multicolumn{2}{|c|}{ Days } & 1 & 2 & 3 & 4 & 5 & 6 & 7 & 8 & 9 & 10 & 11 & 12 & 13 & 14 & 15 & 16 & 17 & 18 & 19 & 20 & 21 & 22 & 23 & & 223 \\
\hline \multirow{2}{*}{\multicolumn{2}{|c|}{$\begin{array}{l}\text { Cement bags } \\
\text { Per-day }\end{array}$}} & & & & & & & & & & & & & & & & & & & & & & & & & \\
\hline & & 5 & 5 & 5 & 0 & 16 & 16 & 16 & 16 & 16 & 13 & 7 & 7 & 7 & 18 & 18 & 18 & 14 & 14 & 6 & 6 & 0 & 0 & 0 & Max & 18 \\
\hline
\end{tabular}

Figure 3. Resource histogram with Bar chart.

Referring to the resource histogram chart it can be explained that activity A doesn't need any resources. As far as first 3 days are concerned only activity $\mathrm{B}$ can be done, which means that B needs 5 cement bags deployment. No resource is allocated on day 4 . But, coming to day 5 , there is possibility of activities $\mathrm{D}$ and $\mathrm{E}$ being carried out. D requires 10 and $\mathrm{E}$ requires 6 , therefore the deployment required as for day 5 is concerned can be 16 cement bags. This continues such that activity E finishes. On day 10 activity B is going on and requires 7 cement bags. Once day 14 is onset, peak demand of resources are achieved and $\mathrm{F}$ requires $12, \mathrm{H}$ requires 6 , hence deployment required until day 16 is 18 cement bags and eventually activity I ends up the project with zero resource requirement. 
Considering the histogram for resource leveling given in figure 4, it can be stated that no more than 18 cement bags used on any day. Maximum number of resources at peak time is provided and the earliest possible Project completion date which is 23 days.

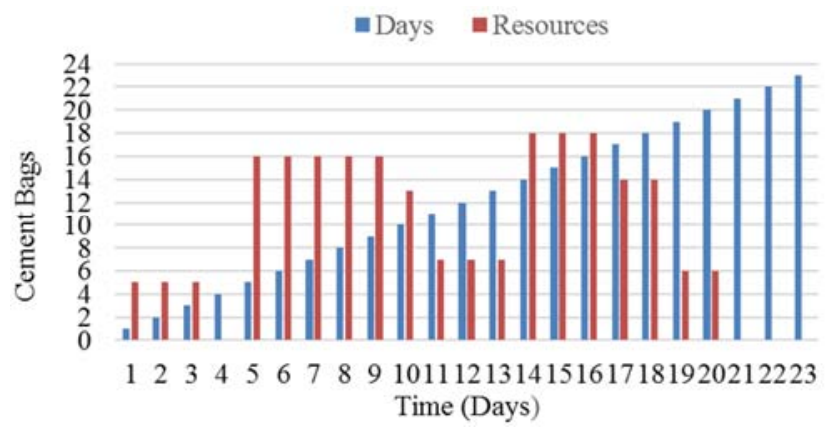

Figure 4. Histogram for resource leveling.

\subsection{Second Scenario}

When the available resource is constrained to 12 cement bags / day, then the total duration of the project is definitely going to be more than 23 days. To perform a constrained resource process, the activity of the project with insufficient resources shall not start. Figure 5 exhibits that number of cement bags is restricted to 12 . Therefore, if $\mathrm{E}$ and $\mathrm{C}$ activities are taken into account to be simultaneously allocated, they require 13 bags of cement, but the available resource is 12 bags, hence can't be assigned. On the other hand, in case of E, $\mathrm{F}, \mathrm{H}$ activities, 24 cement bags needed to do a parallel allocation which can't be executed. Therefore, here activity $\mathrm{F}$ alone or $\mathrm{E}+\mathrm{H}$ activities can be fulfilled simultaneously because their resource requirement is less than 12 cement bags.

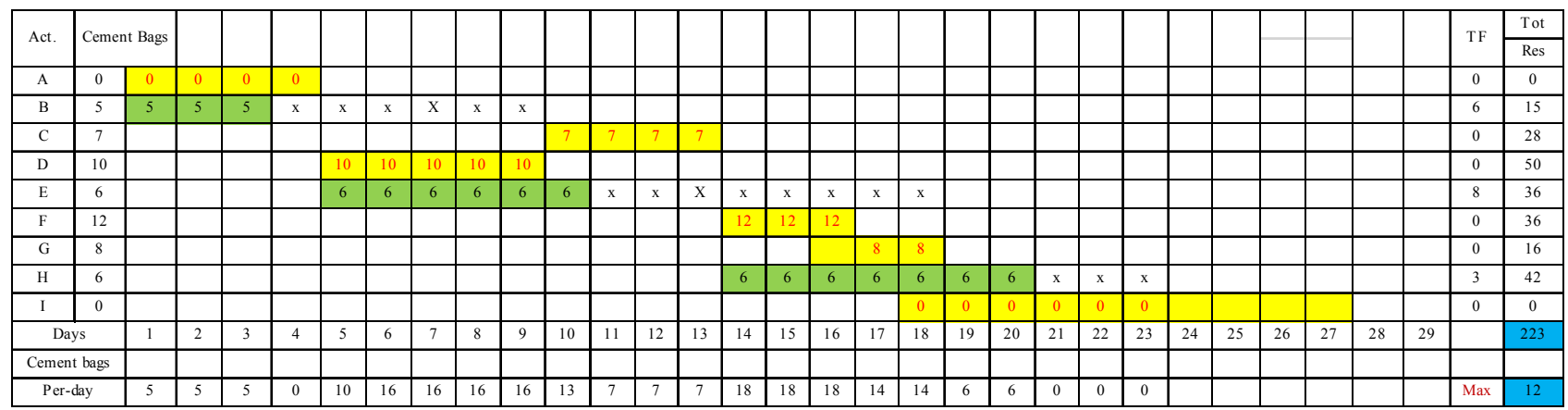

Figure 5. Resource histogram with Gantt chart.

\section{Conclusion}

It is obvious that resource planning and allocation plays an important role in managing construction projects. As real-life projects face resource constraints such as shortage of resources, delayed delivery, competing demand, etc. In this study resource oriented scheduling concepts are considered and their effects on completion of the project are investigated. And it is concluded that when resources are not available in the desired amount or constrained, then the total duration of the project prolongs significantly. Moreover, if the client is satisfied with the condition, then there is not such a big dilemma for the project to be accomplished after 6 days delay. In case the contractor / client isn't satisfied with it, it would be possible by providing more resources and pumping them as much as possible, so a great amount of money will be spent by compromising on profit. Hence, how much cost demand for deploying more resources is essential, can be decided based on cost optimization. As, it is mentionable that the fluctuations are very undesirable for the contractor.

\section{Recommendation}

The proposed model utilizes the straightforward resource-constrained as well as unconstrained project scheduling problem; however, in this model, only renewable resources (e.g. material resources) are considered. In project management, besides renewable, non-renewable resources (e.g., cost demand) may also be significant parameters. Therefore, this extension can be considered in future research.

\section{References}

[1] Eirgash, M. A., Toğan, V., and Dede, T. (2019). “A multi-objective decision-making model based on TLBO for the time-cost trade-off problems.” Struct. Eng. Mech., 71 (2), 139-151.

[2] Toğan, V., and Eirgash, M. A. (2019a). "Time-cost trade-off optimization of construction projects using teaching learning-based optimization.” KSCE J. Civ. Eng., 23 (1), 10-20.

[3] Chen P, Weng H. "A two-phase GA model for resource-constrained project scheduling," AUTOMAT CONSTR, 32 (1), 9-17, 2009.

[4] Wuliang P, Chengen W. "A multi-mode resource-constrained discrete time-cost tradeoff problem and its genetic algorithm based solution," International Journal of Project Management, 201 (2), 09-18, 2009.

[5] Eirgash, M. A., Toğan, V., and Dede, T. Başağa. H. B. "Time-Cost Trade off Optimization for Construction Projects Using an Optimization Engine." Eurasian Journal of Engineering Sciences and Technology, 1 (2017) 54-68.

[6] Castro Lacouture D, Suer GA, Gonzalez Joaqui J, Yates JK. "Construction project scheduling with time, cost, and material restrictions using fuzzy mathematical models and critical path method," J CONSTR ENG M, 135 (10), 1096-104, 2009. 
[7] M. E. Georgy, "Evolutionary resource scheduler for linear projects," Automation in Construction, vol. 17, no. 5, pp. 573583, 2008.

[8] M. H. Elwany, I. E. Korish, M. A. Barakat, and S. M. Hafez, "Resource smoothening in repetitive projects," Computers and Industrial Engineering, vol. 35, no. 3-4, pp. 415-418, 1998.

[9] Rao, Singiresu S. 1976. Journal of the Operational Research Society Engineering Optimization.

[10] Hegazy, Tarek. "Optimization of Resource Allocation and Leveling Using Genetic Algorithms." Journal of construction engineering and management 1999; 125 (3): 167-75.

[11] Iranagh, Mahdi Abbasi, and Rifat Sonmez. "A Genetic Algorithm for Resource Leveling.” 2012; 1047-54.
[12] G. Lucko, "Integrating efficient resource optimization and linear schedule analysis with singularity functions," Journal of Construction Engineering and Management, vol. 137, no. 1, pp. 45-55, 2011.

[13] Garmsiri M, Abassi MR (2012). Resource leveling scheduling by an ant colony-based model. Journal of Industrial Engineering International 8: 1-9.

[14] Khanzadi M, Kaveh A, Alipour M, Aghmiuni HK (2016). Application of CBO and CSS for resource allocation and resource leveling problem. Iranian Journal of Science and Technology, Transactions of Civil Engineering 40: 1-10.

[15] Cheng MY, Tran DH (2015). Opposition-based multiple objective differential evolution (OMODE) for optimizing work shift schedules. Automation in Construction 55: 1-14. 